Trinity University

Digital Commons@ Trinity

Chemistry Faculty Research

Chemistry Department

9-21-2004

\title{
Synthesis and Characterization of Dendrimer Templated Supported Bimetallic Pt-Au Nanoparticles
}

Huifang Lang

Trinity University

S. Maldonado

K.J. Stevenson

Bert D. Chandler

Trinity University, bchandle@trinity.edu

Follow this and additional works at: https://digitalcommons.trinity.edu/chem_faculty

Part of the Chemistry Commons

\section{Repository Citation}

Lang, H., Maldonado, S., Stevenson, K. J., \& Chandler, B. D. (2004). Synthesis and characterization of dendrimer templated supported bimetallic pt-au nanoparticles. Journal of the American Chemical Society, 126(40), 12949-12956.

This Article is brought to you for free and open access by the Chemistry Department at Digital Commons @ Trinity. It has been accepted for inclusion in Chemistry Faculty Research by an authorized administrator of Digital Commons @ Trinity. For more information, please contact jcostanz@trinity.edu. 


\title{
Synthesis and Characterization of Dendrimer Templated Supported Bimetallic Pt-Au Nanoparticles
}

\author{
Huifang Lang, ${ }^{\dagger}$ Stephen Maldonado, ${ }^{\ddagger}$ Keith J. Stevenson, ${ }^{\ddagger}$ and Bert D. Chandler ${ }^{\star, \dagger}$ \\ Department of Chemistry, Trinity University, One Trinity Place, San Antonio, Texas 78212-7200, \\ and Department of Chemistry, University of Texas at Austin, 1 University Station A5300,
} Austin, Texas 78712-0165

Received June 11, 2004; E-mail: bert.chandler@trinity.edu

\begin{abstract}
Bimetallic dendrimer-stabilized nanoparticles (DSNs) were used to prepare supported $\mathrm{Pt}-\mathrm{Au}$ catalysts within the bulk miscibility gap for this binary system. Hydroxy-terminated generation 5 PAMAM dendrimers were used to prepare $\mathrm{Cu}^{0}$ nanoparticles (NPs). The $\mathrm{Cu}^{0} \mathrm{NPs}$ were subsequently used to reduce $\mathrm{K}_{2} \mathrm{PtCl}_{4}$ and $\mathrm{HAuCl}_{4}$, preparing stabilized bimetallic $\mathrm{Pt}-\mathrm{Au}$ NPs with a 1:1 stoichiometry. The stabilized NPs were adsorbed onto a high surface area silica support and thermally activated to remove the dendrimers. Transmission electron microscopy (TEM), energy dispersive spectroscopy (EDS), and infrared spectroscopy of adsorbed $\mathrm{CO}$ showed that this preparation route resulted in NPs in which the two metals are intimately mixed and that the majority of the bimetallic NPs were smaller than $3 \mathrm{~nm}$. Further, the bimetallic NPs were highly active for $\mathrm{CO}$ oxidation catalysis near room temperature and showed evidence of $\mathrm{CO}$ induced restructuring at ambient temperatures.
\end{abstract}

\section{Introduction}

Finely dispersed metal NPs, supported on inorganic oxide carriers, are a mainstay of commercial heterogeneous catalysts and are employed in numerous industrial reactions, ${ }^{1}$ automotive catalytic converters, ${ }^{2,3}$ and fuel cell technologies. ${ }^{2,4}$ Bimetallic platinum based catalysts in particular are widely used in industry and for proton exchange membrane (PEM) fuel cells. The discovery of gold based catalysts with extraordinarily high catalytic activity for low-temperature $\mathrm{CO}$ oxidation, ${ }^{5,6}$ as well as the potential application of gold NPs in catalysis, ${ }^{7}$ and nanotechnology ${ }^{8}$ have fueled recent interest in gold chemistry and gold based materials.

Supported bimetallic Pt-Au NPs are of similar fundamental interest and importance. The effects of heterometals (e.g., Pt) on the surface chemistry and catalytic properties of gold based NPs are largely unknown. ${ }^{7}$ Further, gold is one of only two transition metals more electronegative than platinum, ${ }^{9}$ so the incorporation of $\mathrm{Au}$ into Pt NPs may have unique effects on catalysis by Pt. Recent interests in the Pt-Au NPs have centered on their optical properties, ${ }^{10}$ their potential as selective oxida-

\footnotetext{
$\dagger$ Trinity University.

$\doteqdot$ University of Texas at Austin.

(1) Ponec, V.; Bond, G. C. Catalysis by Metals and Alloys; Elsevier: Amsterdam, 1995; Vol. 95.

(2) Heck, R. M.; Farrauto, R. J. Appl. Catal., A 2001, 221, 443-457.

(3) Bhattacharyya, S.; Das, R. K. Int. J. Energ. Res. 1999, 23, 351-369.

(4) Song, C. S. Catal. Today 2002, 77, 17-49.

(5) Haruta, M.; Yamada, N.; Kobayashi, T.; Iijima, S. J. Catal. 1989, 115, 301.

(6) Haruta, M.; Tsubota, S.; Kobayashi, T.; Kageyama, H.; Genet, M. J.; Delmon, B. J. Catal. 1993, 144, 175.

(7) Bond, G. C.; Thompson, D. T. Catal. Rev. Sci. Eng. 1999, 41, 319-388.

(8) Daniel, M.-C.; Astruc, D. Chem. Rev. 2004, 104, 293-346.

(9) Allred, A. L. J. Inorg. Nucl. Chem. 1961, 17, 215

(10) Shiraishi, T.; Hisatsune, K.; Tanaka, Y.; Miura, E.; Takuma, Y. Gold Bull. 2001, 34, 129-133.

10.1021/ja046542o CCC: $\$ 27.50$ @ 2004 American Chemical Society
}

tion $^{11,12}$ and dehydrogenation ${ }^{13}$ catalysts, electrocatalysts, ${ }^{14}$ and selective sensors. ${ }^{15}$ Cationic $\mathrm{Pt}-\mathrm{Au}$ clusters have also recently been shown to have unique reactivity for $\mathrm{C}-\mathrm{N}$ coupling of methane and ammonia. ${ }^{16,17}$

Silica is an attractive support for studying NP and catalyst properties because it is only mildly acidic, is relatively inert, and has desirable mechanical properties. Gold particles are extremely mobile on silica surfaces ${ }^{13,18,19}$ and readily form very large $(50+\mathrm{nm})$ unreactive particles when treated at elevated temperatures, thus making the preparation of active $\mathrm{Au} / \mathrm{SiO}_{2}$ catalysts difficult. ${ }^{20}$ Previous attempts to prepare $\mathrm{Pt}-\mathrm{Au} / \mathrm{SiO}_{2}$ catalysts via traditional impregnation methods have resulted in widespread phase segregation and catalysts containing large particle agglomerates. ${ }^{11,13,21-24}$ In some cases, the coexistence

(11) Mihut, C.; Descorme, C.; Duprez, D.; Amiridis, M. D. J. Catal. 2003, 212, $125-135$.

(12) Vazquez-Zavala, A.; Garcia-Gomez, J.; Gomez-Cortes, A. Appl. Surf. Sci. 2000, 167, 177-183

(13) Shen, J.; Hill, J. M.; Ramachandra, M. W.; Podkolzin, S. G.; Dumesic, J. A. Catal. Lett. 1999, 60, 1-9.

(14) Lou, Y.; Maye, M. M.; Han, L.; Luo, J.; Zhong, C. J. Chem. Commun. 2001, 5, 473.

(15) Skelton, D. C.; Wang, H.; Tobin, R. G.; Lambert, D. K.; Dimaggio, C. L.; Fisher, G. B. J. Phys. Chem. B 2001, 105, 204-209.

(16) Koszinowski, K.; Schroder, D.; Schwartz, H. Organometallics 2004, 23 $1132-1139$.

(17) Koszinowski, K.; Schroder, D.; Schwartz, H. Angew. Chem., Int. Ed. 2004 $43,121-124$

(18) Wolf, A.; Schuth, F. Appl. Catal., A 2002, 226, 1-13.

(19) Yang, C.-m.; Kalwei, M.; Schuth, F.; Chao, K.-j. Appl. Catal., A 2003 254, 289-296.

(20) Wolf, A.; Schuth, F. Appl. Catal., A 2002, 226, 1-13.

(21) Schwank, J.; Balakrishnan, K.; Sachdev, A. In New Frontiers in Catalysis: Proceedings of the 10th International Congress on Catalysis; Solymosi, F., Ed.; Elsevier: Amsterdam, 1993; pp 905-918.

(22) Chandler, B. D.; Schabel, A. B.; Blanford, C. F.; Pignolet, L. H. J. Catal. 1999, 367-383.

(23) Balakrishnan, K.; Sachdev, A.; Schwank, J. J. Catal. 1990, 121, 441445 .

(24) Sachdev, A.; Schwank, J. J. Catal. 1989, 120, 353-369. 
of bimetallic Pt-Au NPs was also identified. ${ }^{13,21,23,24}$ Bimetallic $\mathrm{Pt}-\mathrm{Au}$ NPs within the miscibility gap can also be prepared in zeolites by using the zeolite supercages to arrest particle agglomeration and trap bimetallic NPs. ${ }^{25}$

Inorganic and organometallic cluster compounds have also been used to successfully prepare novel bimetallic catalysts. ${ }^{26}$ In this route, ligand-stabilized molecular clusters, typically stabilized by $\mathrm{CO}$ ligands, are deposited onto oxide supports and thermally activated to remove the ligands. This method has led to the preparation of several bimetallic $\mathrm{Pt}-\mathrm{Au} / \mathrm{SiO}_{2}$ catalysts in which the metals are intimately mixed after ligand removal. ${ }^{11,22,27-29}$ Unfortunately, the solution chemistry of $\mathrm{Pt}-\mathrm{Au}$ clusters is dominated by the utilization of phosphine ligands, ${ }^{30}$ which are extremely difficult to remove from the ultimate catalyst and are severe poisons for many reactions. ${ }^{27-30}$ Several catalysts have also been prepared from an organometallic acetylide-ligated $\mathrm{Pt}_{2} \mathrm{Au}_{4}$ cluster. ${ }^{11,22}$ These catalysts have shown novel reactivity arising from the intimate mixing of $\mathrm{Pt}$ and $\mathrm{Au}$, particularly in hydrocarbon conversion reactions ${ }^{22,31}$ and in the selective catalytic reduction of nitrogen oxides. ${ }^{11}$ However, Pt:Au metal ratios cannot be varied without an extensive cluster library, which does not exist for nonphosphine $\mathrm{Pt}-\mathrm{Au}$ clusters.

Recent advances in NP (NP) preparation techniques ${ }^{8,32,33}$ offer new opportunities for the preparation of supported bimetallic catalysts. In this process, which is analogous to the cluster route, surface protected mono- or bimetallic NPs are prepared in solution, deposited onto a support, and the colloid stabilizers are removed yielding supported particles with known, characterizable, and reproducible synthetic histories. Because NP compositions may be within bulk miscibility gaps, the colloid method also offers opportunities to prepare and investigate new bimetallic NP catalysts in a rational, controlled fashion. Further, heterogeneous catalysis and some catalyst characterization techniques directly probe the surface chemistry of supported NPs and thus can be considered additional tools in the investigation of NP chemistry and the discovery of new NP properties.

We recently presented a "proof of concept" for this catalyst preparation method using PAMAM dendrimers as NP templates/ stabilizers. ${ }^{34}$ Dendrimer-stabilized Pt NPs were prepared in aqueous solution, deposited onto a commercial high surface area silica support, and thermally activated to yield supported Pt NPs that were active for $\mathrm{CO}$ oxidation and toluene hydrogenation test reactions. These results also showed that PAMAM dendrimers could be completely removed at $300{ }^{\circ} \mathrm{C}$, although the

(25) Riahi, G.; Guillemot, D.; Polisset-Thfoin, M.; Khodadadi, A. A.; Fraissard, J. Catal. Today 2002, 72, 115-121.

(26) Alexeev, O.; Gates, B. C. Ind. Eng. Chem. Res 2003, 42, 1571-1587.

(27) Chandler, B. D.; Rubinstein, L. I.; Pignolet, L. H. J. Mol. Catal., A 1998 133, 267-282.

(28) Yuan, Y. Z.; Asakura, K.; Wan, H. L.; Tsai, K. R.; Iwasawa, Y. J. Mol. Catal., A 1997, 122, 147-157.

(29) Yuan, Y. Z.; Asakura, K.; Wan, H. L.; Tsai, K. R.; Iwasawa, Y. Bull. Chem. Soc. Jpn. 1999, 72, 2643-2653

(30) Pignolet, L. H.; Krogstsad, D. A. In Gold: Progress in Chemistry, Biochemistry, and Technology; Schmidbaur, H., Ed.; Wiley and Sons: Chichester, U.K., 1999; pp 429-493.

(31) Chandler, B. D.; Schabel, A. B.; Pignolet, L. H. J. Phys. Chem. B 2001, $105,149-155$.

(32) Brust, M.; Kiely, C. J. Colloids Surf., A 2002, 202, 175-186.

(33) Crooks, R. M.; Zhao, M.; Sun, L.; Chechik, V.; Yeung, L. K. Acc. Chem. Res. 2001, 34, 181-190.

(34) Lang, H.; May, R. A.; Iversen, B. L.; Chandler, B. D. J. Am. Chem. Soc. 2003, 125, 14832-14836. time required to remove organic residues may vary with metal: dendrimer ratio. ${ }^{35}$

This manuscript describes the development of this general preparative scheme for a new class of bimetallic NP catalysts. Although $\mathrm{Pt}-\mathrm{Au} / \mathrm{SiO}_{2}$ system is synthetically challenging to explore, the substantial differences in the surface chemistry of $\mathrm{Pt}$ and $\mathrm{Au}$ allows for the evaluation of properties that are distinct to each metal. We have also chosen to work well within the miscibility gap as this provides the opportunity to prepare catalysts that are not attainable by traditional routes.

\section{Results and Discussion}

Preparation and Definition of Materials. Dendrimer encapsulated Pt or Pd NPs can be prepared by first complexing $\mathrm{PtCl}_{4}{ }^{2-}$ ions to the interior amine groups of hydroxyl terminated PAMAM dendrimers, then adding a strong reducing agent (e.g., $\left.\mathrm{NaBH}_{4}\right) .{ }^{33}$ Co-complexation of two metal precursors has led to the preparation of several bimetallic NP systems, including Pt$\mathrm{Pd},{ }^{33,36} \mathrm{Pd}-\mathrm{Rh},{ }^{37}$ and $\mathrm{Pd}-\mathrm{Ag}^{38} \mathrm{NPs}$. In solution, the $\mathrm{Pt}-\mathrm{Pd}^{33,36}$ and $\mathrm{Pd}-\mathrm{Rh}^{37}$ systems are both active hydrogenation catalysts and exhibit a synergy in catalytic activity that correlates to NP composition.

The large standard potential of the aurate ion $(+1.00 \mathrm{~V}$ vs $\mathrm{NHE})^{39}$ makes the preparation of $\mathrm{Pt}-\mathrm{Au}$ NPs more challenging. Aqueous mixtures of platinum(II) and gold(III) chloride salts are thermodynamically unstable, ${ }^{39}$ and gold(III) rapidly oxidizes the $\mathrm{Pt}(\mathrm{II})$ complexes appropriate for binding to dendrimer amine groups. Further, $\mathrm{Au}(\mathrm{III})$ is not stable in the presence of hydroxyl terminated dendrimers, as it can oxidize the hydroxyl groups (forming larger $\mathrm{Au}^{0} \mathrm{NPs}$ ) in the absence of an additional reducing agent. ${ }^{40,41}$ To minimize these effects, we have modified a preparative method originally reported by Crooks et al. ${ }^{42}$ In this " $\mathrm{Cu}$ exchange" method (Scheme 1), Cu NPs are initially prepared under $\mathrm{N}_{2}$ inside G5-OH PAMAM dendrimers. Oxygenfree solutions of $\mathrm{K}_{2} \mathrm{PtCl}_{4}$ and $\mathrm{HAuCl}_{4}$ are prepared, mixed, and immediately added to the $\mathrm{Cu}$ NPs (under nitrogen), utilizing the $\mathrm{Cu}^{0}$ NPs as an in-situ reducing agent for both Pt and Au. For this study, the final noble metal:dendrimer ratio was held constant (32:1) by adjusting the initial $\mathrm{Cu}$ :dendrimer ratio used in NP preparation to account for two- and three-electron reductions of $\mathrm{Pt}$ and $\mathrm{Au}$, respectively. The noble metal: dendrimer ratio is well below ratios $\mathrm{we}^{34}$ and others ${ }^{43}$ have used to prepare monometallic Pt and Au DSNs in G5-OH and smaller PAMAM dendrimers.

Figure 1 shows solution $\mathrm{UV}-$ vis spectra of G5-OH( $\left(\mathrm{Pt}_{32}\right)$, G5$\mathrm{OH}\left(\mathrm{Au}_{32}\right)$, and $\mathrm{G} 5-\mathrm{OH}\left(\mathrm{Pt}_{16} \mathrm{Au}_{16}\right)$ immediately prior to surface deposition. The Pt-only sample is characterized by a monotonically increasing absorbance at decreasing wavelengths, consistent with literature reports for Pt-dendrimer nanocomposites. ${ }^{33}$ The low-energy peak $(280 \mathrm{~nm})$ is assigned to an LMCT band

(35) Lang, H.; May, R. A.; Iversen, B. L.; Chandler, B. D. In Catalysis of Organic Reactions; Sowa, J., Ed.; Marcel Dekker: 2004, in press.

(36) Scott, R. W. J.; Datye, A. K.; Crooks, R. M. J. Am. Chem. Soc. 2003, 125 3708-3709.

(37) Chung, Y. M.; Rhee, H. K. J. Mol. Catal., A 2003, 206, 291-298.

(38) Chung, Y. M.; Rhee, H. K. J. Colloid Interface Sci. 2004, 271, 131-135.

(39) Latimer, W. M. The Oxidation States of the Elements and their Potentials in Aqueous Solutions, 2nd ed.; Prentice-Hall: New York, 1953.

(40) West, R.; Wang, Y.; Goodson, T. J. Phys. Chem. B 2003, 107, 34193426.

(41) Esumi, K.; Hosoya, T.; Suzuki, A.; Torigoe, K. Langmuir 2000, 16, $2978-$ 2980.

(42) Zhao, M. Q.; Crooks, R. M. Chem. Mater. 1999, 11, 3379-3385.

(43) Kim, Y.-G.; Oh, S.-K.; Crooks, R. M. Chem. Mater. 2004, 16, 167-172. 
Scheme 1
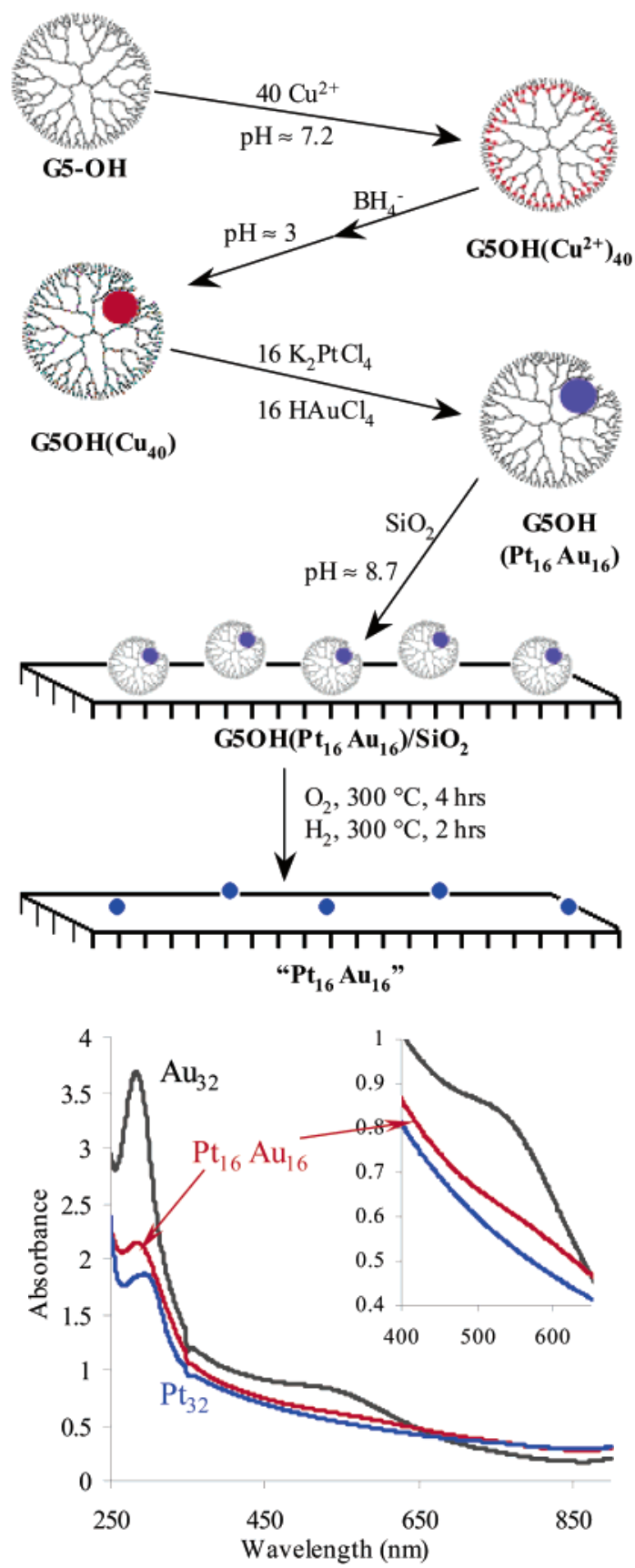

Figure 1. $\mathrm{UV}$-vis spectra for $\mathrm{Pt}_{32}$ (blue), $\mathrm{Au}_{32}$ (black), and $\mathrm{Pt}_{16} \mathrm{Au}_{16}$ (red) DSNs in solution.

from residual $\mathrm{Cu}(\mathrm{II})$-dendrimer complexes. ${ }^{33}$ The Au-only sample has similar features with an additional shoulder from 500 to $600 \mathrm{~nm}$. This shoulder is consistent with the plasmon band arising from Au NPs larger than $2 \mathrm{~nm} .{ }^{43,44}$ The bimetallic $\mathrm{Pt}_{16} \mathrm{Au}_{16}$ spectrum is generally similar to the spectrum of $\mathrm{Pt}_{32}$ and the Au-plasmon band around 530 is not present. There is also a very weak shoulder at around $600 \mathrm{~nm}$ that correlates very well with the visible ligand-field transitions in $\mathrm{Cu}$ (II)-dendrimer complexes. ${ }^{33}$ We cannot rule out the possibility that this band is due to the presence of larger Au agglomerates, although we found no evidence for such species in our TEM studies (vida infra).

(44) Alvarez, M. M.; Khoury, J. T.; Schaaff, T. G.; Shafigullin, M. N.; Vezmar, I.; Whetten, R. L. J. Phys. Chem. B 1997, 101, 3706-3712.
Table 1. Catalyst Preparation and Characterization Data

\begin{tabular}{|c|c|c|c|c|}
\hline & $\mathrm{Pt}_{32}$ & $\mathrm{Au}_{32}$ & $\mathrm{Pt}_{16} \mathrm{Au}_{16}$ & $\mathrm{Pt}_{32}+\mathrm{Au}_{32}$ \\
\hline nominal Cu:Dendrimer ${ }^{a}$ & 32 & 48 & 40 & 32,48 \\
\hline Pt loading (wt. $\%)^{b}$ & $0.25 \%$ & & $0.14 \%$ & $0.14 \%$ \\
\hline Au loading (wt. $\%)^{b}$ & & $0.29 \%$ & $0.15 \%$ & $0.15 \%$ \\
\hline $\mathrm{Pt}: \mathrm{Au} \operatorname{ratio}^{c}$ & & & $15: 17$ & $15: 17$ \\
\hline$d_{\mathrm{ave}}(\mathrm{nm})^{d}$ & 3.3 & 14.5 & 2.6 & 4.2 \\
\hline standard deviation $^{e}$ & 0.8 & 14.8 & 1.1 & 4.2 \\
\hline $\mathrm{d}_{\mathrm{MP}}(\mathrm{nm})^{f}$ & 3.5 & 12 & 2.0 & 3.0 \\
\hline
\end{tabular}

${ }^{a} \mathrm{Cu}$ :dendrimer stoichiometry. ${ }^{b}$ Supported catalyst \% Pt and Au, determined by atomic absorpton spectroscopy. $\mathrm{Cu}$ content was also measured for all catalysts and was always below detection limits $(0.01 \%) .{ }^{c}$ Determined from $\mathrm{Pt}$ and Au loadings. ${ }^{d}$ Arithmetic mean diameter of all imaged particles. ${ }^{e}$ Standard deviation in $d_{\text {ave }}{ }^{f}$ Most probable diameter: The observed particle diameter that occurs with the highest frequency, i.e., the highest bar on the PSDs in Figure 2. This quantity allows offers an additional means of comparing different types of distributions (e.g., Gaussian vs Maxwell-Boltzman)

The dendrimer-stabilized NPs (DSNs) are then adsorbed onto silica ${ }^{34}$ and washed with EDTA solution to remove the remaining $\mathrm{Cu}$. Numerous washing techniques were evaluated; the protocol described here always resulted in $\mathrm{Cu}$ content below detection limits $(0.01 \% \mathrm{Cu})$. The supported DSNs were activated under flowing $\mathrm{O}_{2}\left(300{ }^{\circ} \mathrm{C}, 4 \mathrm{~h}\right)$ followed by reduction with flowing $\mathrm{H}_{2}\left(300{ }^{\circ} \mathrm{C}, 2 \mathrm{~h}\right)$. This thermolysis treatment has previously been shown to remove PAMAM dendrimers from silica supported monometallic Pt DSNs without causing measurable particle agglomeration. ${ }^{34}$ It is possible that some organic residues remain after the standard pretreatment; however, this activation protocol removes $95+\%$ of the $\mathrm{C}$ and $\mathrm{N}^{34}$ and provides a reasonable starting point for evaluating new catalysts.

Using this general preparative scheme, a substantial number of compositionally important factors (beyond the Pt:Au and metal:dendrimer ratios) can be varied. The total metal loading metal:dendrimer ratio and dendrimer loading are important parameters for the deposition and activation of DSNs; maintaining consistent dendrimer loadings is particularly important for comparing dendrimer derived catalysts. ${ }^{34,35}$ For this study, the final metal:dendrimer ratio was held constant (32:1) and silica masses were adjusted to fix both the total metal (ca. 0.3 wt. \% metal) and dendrimer loading. Final metal ratios were determined by atomic absorption (AA) spectroscopy (Table 1) and were always close to the expected values. The Pt:Au ratio was initially set to be approximately $1: 1$, as this ratio is within the bulk miscibility gap and represents a metal ratio not available through cluster precursors.

For comparison, three additional materials were prepared. We have chosen a nomenclature system that indicates the stoichiometric metal:metal and metal:dendrimer ratios used in catalyst preparation. The primary material of interest is termed the bimetallic catalyst defined as $\mathrm{Pt}_{16} \mathrm{Au}_{16}$. The monometallic $\mathrm{Pt}$ and $\mathrm{Au}$ materials $\left(\mathrm{Pt}_{32}\right.$ and $\mathrm{Au}_{32}$, respectively) were prepared to evaluate the behavior of each metal in the absence of the other. An additional advantage of the dendrimer route for bimetallic catalyst preparation is that it offers the opportunity to prepare an additional control material containing both metals. Consequently, we individually prepared monometallic Pt and $\mathrm{Au}$ NP solutions via $\mathrm{Cu}$ displacement, combined them, and simultaneously deposited them on to silica. We describe this material $\left(\mathrm{Pt}_{32}+\mathrm{Au}_{32}\right)$ as a "cometallic" to distinguish it from the "bimetallic" $\mathrm{Pt}_{16} \mathrm{Au}_{16}$. Although both materials contain both metals with the same metal ratios and loadings, $\mathrm{Pt}_{32}+\mathrm{Au}_{32}$ has 

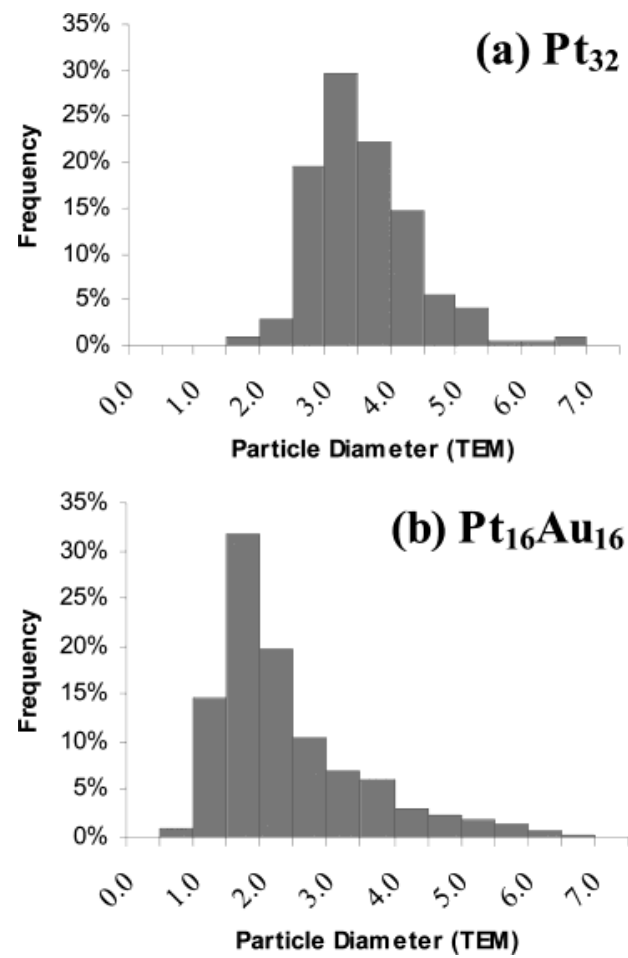

Figure 2. TEM particle size distributions for $\mathrm{Pt}_{32}$ and $\mathrm{Pt}_{16} \mathrm{Au}_{16}$.

been intentionally prepared to have little or no interactions between the monometallic NPs. In contrast, the bimetallic $\mathrm{Pt}_{16} \mathrm{Au}_{16}$ has been prepared with the goal of forming bimetallic NPs in which Pt and Au are intimately mixed.

Transmission Electron Microscopy. Table 1 includes bulk characterization data for all four materials, as well as a summary of the TEM data. Representative particle size distributions (PSDs) for $\mathrm{Pt}_{32}$ and $\mathrm{Pt}_{16} \mathrm{Au}_{16}$ are shown in Figure 2. Additional PSDs and representative TEM micrographs are provided in the Supporting Information. Particle sizes for $\mathrm{Pt}_{32}$ are larger than those observed for catalysts prepared by direct complexation ${ }^{34}$ and suggest that $\mathrm{Cu}$ displacement leads to Pt NPs stabilized by several dendrimers. The particles on $\mathrm{Au}_{32}$ are substantially larger with $15 \%$ of the observed particles larger than $20 \mathrm{~nm}$. This indicates that sintering is a substantial problem for $\mathrm{Au} / \mathrm{SiO}_{2}$

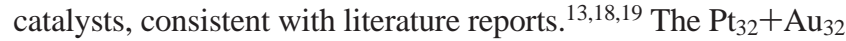
PSD contains features of the PSDs from both monometallic catalysts, although the most probable diameter $\left(d_{\mathrm{MP}}\right)$ is slightly lower than for $\mathrm{Pt}_{32}$. A similar effect has been reported for $\mathrm{Pt}-$ $\mathrm{Au} / \mathrm{SiO}_{2}$ catalysts prepared from the impregnation of chloride salts, suggesting that the presence of Au affects Pt particle sizes by preventing the formation of large Pt particles. ${ }^{21-24}$

TEM studies of $\mathrm{Pt}_{16} \mathrm{Au}_{16}$ indicate that the particles are substantially smaller than the other catalysts. The $\mathrm{Pt}_{16} \mathrm{Au}_{16}$ PSD is similar to a Maxwell-Boltzman distribution, making the most probable diameter $\left(d_{\mathrm{MP}}\right)$ a more practical tool for describing the majority of the imaged particles. Notably, $75 \%$ of the imaged particles were smaller than $3 \mathrm{~nm}$. No particles larger than $7 \mathrm{~nm}$ were observed, in striking contrast to the other $\mathrm{Au}$ containing materials, suggesting that the $\mathrm{Cu}$ exchange synthesis leads to bimetallic particles that are substantially more resistant to sintering than monometallic Au.

$\mathrm{Pt}_{16} \mathrm{Au}_{16}$ was also examined with $\mathrm{X}$-ray energy dispersive spectroscopy (EDS) during high-resolution TEM experiments (Figure 3). The average Pt composition (14 measurements) was

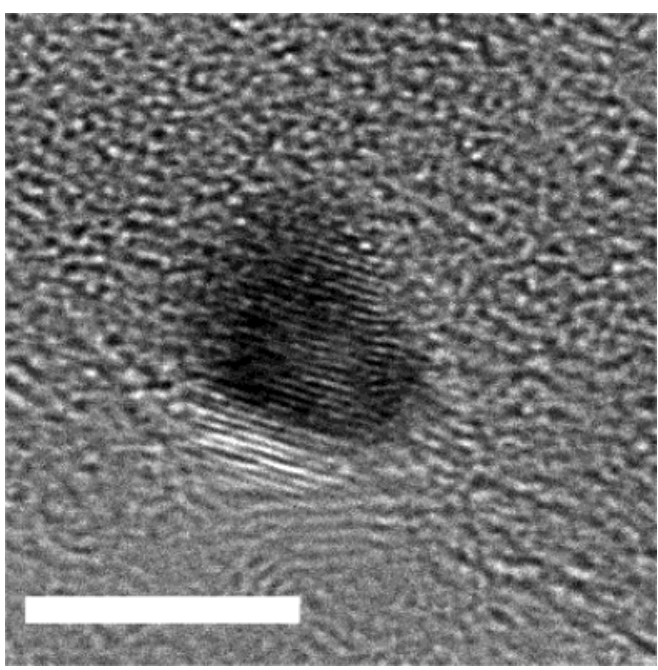

Figure 3. High-resolution TEM image from $\mathrm{Pt}_{16} \mathrm{Au}_{16}$. Scale bar is $5 \mathrm{~nm}$.

$40 \%$ Pt with a $25 \%$ standard deviation. This value is in reasonable agreement with the bulk AA measurements for the catalyst $(48 \% \mathrm{Pt})$, especially considering that that EDS measurements are difficult to calibrate because of lack of available standards. However, EDS alone is insufficient to properly identify the nature of elemental distribution of small particles. Further electron beam diffraction studies are necessary to differentiate between a phase-segregated platinum/gold composition from a homogeneous distribution of platinum and gold atoms. Nevertheless, the analysis presented here represents strong evidence for the bimetallic nature of the $\mathrm{Pt}_{16} \mathrm{Au}_{16} \mathrm{NPs}$.

Infrared Spectroscopy. Infrared spectroscopy of adsorbed $\mathrm{CO}$ is an important characterization tool for NPs as it directly probes their surface features. Figure 4 shows IR spectra of CO adsorbed on the Pt containing materials. No CO adsorption was detected on $\mathrm{Au}_{32}$ (spectrum in Supporting Materials), consistent with large Au particles being chemically inert. ${ }^{7}$ In Figure 4a, the infrared spectrum of $\mathrm{CO}$ adsorbed on $\mathrm{Pt}_{32}$ shows a strong absorption band at $2085 \mathrm{~cm}^{-1}$, consistent with supported $\mathrm{Pt}$ catalysts $^{45}$ and with other dendrimer derived Pt catalysts. ${ }^{34}$ The IR spectrum of $\mathrm{Pt}_{32}+\mathrm{Au}_{32}$ (Figure 4c) largely resembles that of $\mathrm{Pt}_{32}$. It is somewhat less symmetric, with tailing at lower energies. This asymmetry suggests that most surface sites are consistent with Pt NPs. However, the asymmetry also suggests that that there is some degree of surface site heterogeneity that is distinct from the monometallic Pt material.

IR spectra of $\mathrm{Pt}_{16} \mathrm{Au}_{16}$ (Figure 4b) are substantially different from $\mathrm{Pt}_{32}$ and $\mathrm{Pt}_{32}+\mathrm{Au}_{32}$ and are consistent with the preparation of highly dispersed supported, intimately mixed bimetallic NPs. ${ }^{11,22}$ Immediately noticeable is the high-energy absorption band $\left(2113 \mathrm{~cm}^{-1}\right)$, which is consistent with $\mathrm{CO}$ bound to $\mathrm{Au}$ surface sites and supports the existence of bimetallic NPs. ${ }^{11,13,27}$ Further, this peak clearly shows that a substantial fraction of the $\mathrm{Au}$ atoms is reactive and capable of binding $\mathrm{CO}$. The $\mathrm{CO}$ giving rise to this band is bound weakly to the surface and slowly desorbs with continued purging at room temperature. This desorption is responsible for the continued observation of gas-phase CO (periodic oscillations below $2143 \mathrm{~cm}^{-1}$ ). On the basis of the amplitude of these oscillations, the gas-phase concentration of $\mathrm{CO}$ is approximately $10 \mathrm{ppm}$.

(45) Hollins, P. Surf. Sci. Rep. 1992, 16, 51. 

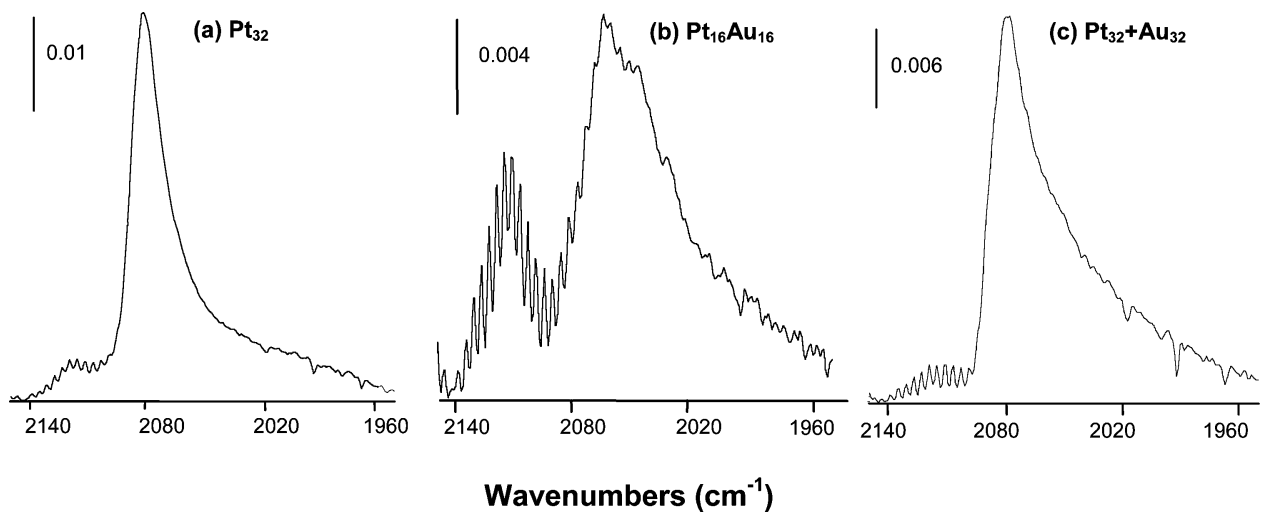

Figure 4. Infrared spectroscopy of $\mathrm{CO}$ adsorbed at $30{ }^{\circ} \mathrm{C}$ on (a) $\mathrm{Pt}_{32}$, (b) $\mathrm{Pt}_{32}+\mathrm{Au}_{32}$, and (c) $\mathrm{Pt}_{16} \mathrm{Au}_{16}$.
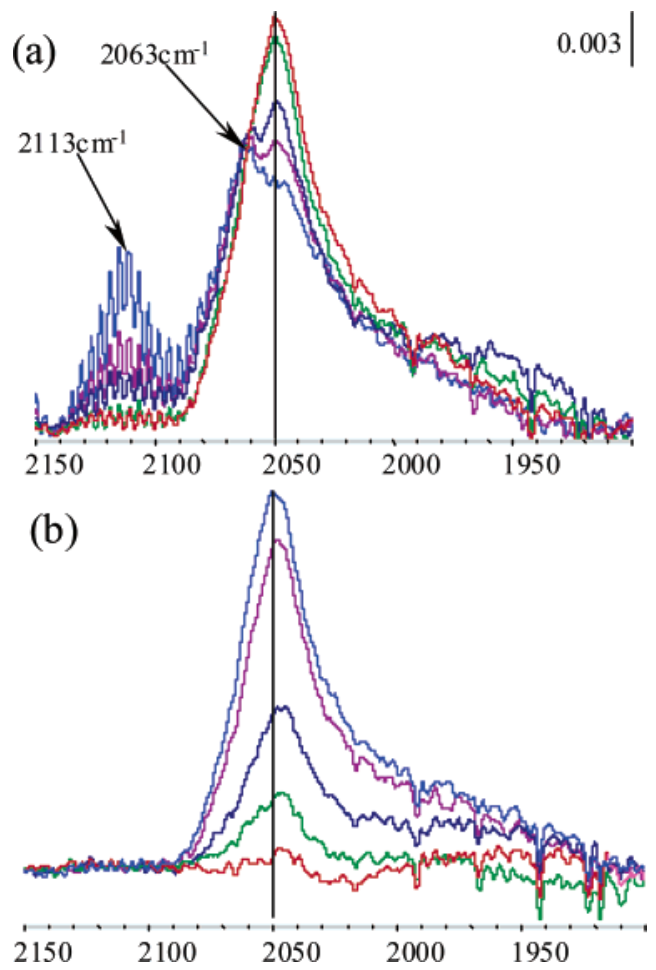

Figure 5. Infrared spectroscopy during $\mathrm{CO}$ desorption from $\mathrm{Pt}_{16} \mathrm{Au}_{16}$ (a) 30 [blue], 70, 90, and 120 [red] ${ }^{\circ} \mathrm{C}$ and (b) 120 [blue], 150, 170, 180, and 190 [red] ${ }^{\circ} \mathrm{C}$

The lower energy band in Figure $4 \mathrm{~b}\left(2063 \mathrm{~cm}^{-1}\right)$ is consistent with $\mathrm{CO}$ bound $\mathrm{Pt}$, as it is strongly bound to the surface and is not readily removed at room temperature. This band is broader than the peak on $\mathrm{Pt}_{32}$ or on other dendrimer derived $\mathrm{Pt} \mathrm{NPs}^{34}$ and red shifted $20 \mathrm{~cm}^{-1}$ relative to $\mathrm{CO}$ on monometallic Pt NPs. This result is also consistent with the presence of a bimetallic surface, where surface Pt atoms are diluted in Au. The physical separation of diluted $\mathrm{Pt}-\mathrm{CO}$ dipoles would reduce their ability to participate in dipole coupling, resulting in an apparent red shift relative to a pure Pt surface. ${ }^{45}$

The spectra in Figure 4 were recorded after dosing the samples with $\mathrm{CO}$ at room temperature and flushing the gasphase $\mathrm{CO}$ from the sample chamber with flowing helium. Heating the sample while continuing to flush with He (Figure 5) caused further change to the infrared spectrum. In Figure 5a, $\mathrm{Au}-\mathrm{CO}$ band disappears quickly, consistent with $\mathrm{CO}$ being weakly bound to $\mathrm{Au}$ on silica supported $\mathrm{Pt}-\mathrm{Au}$ NPs. The disappearance of the $\mathrm{Au}-\mathrm{CO}$ band also coincides with an increase in the $\mathrm{Pt}-\mathrm{CO}$ band intensity. In contrast, when $\mathrm{Pt}_{32}$ is
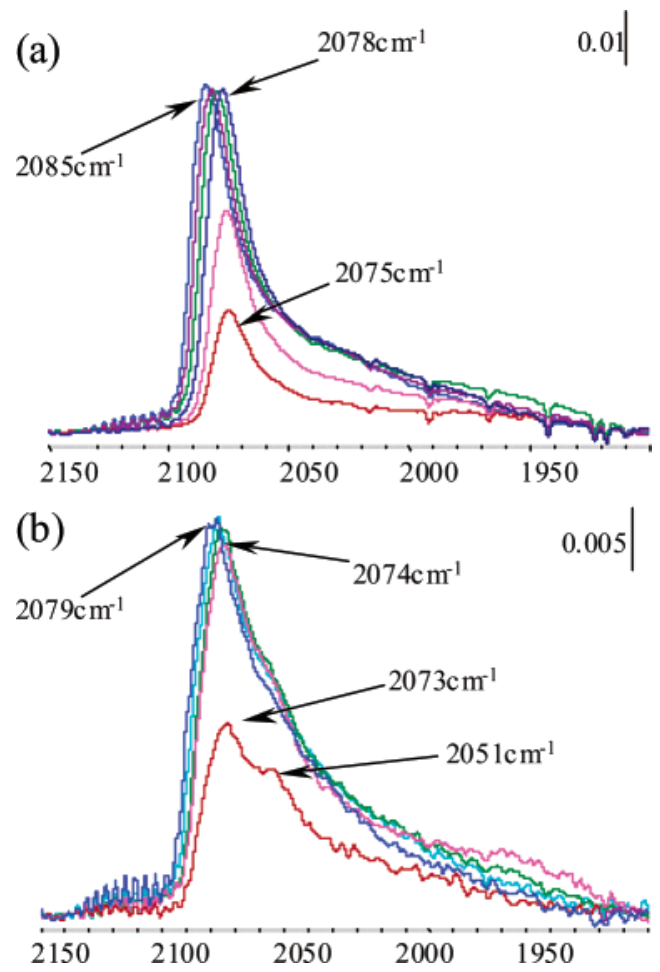

Figure 6. Infrared spectroscopy during $\mathrm{CO}$ desorption from (a) $\mathrm{Pt}_{32} 40$ [blue], 70, 100, 130, 140, and 145 [red] ${ }^{\circ} \mathrm{C}$ and (b) $\mathrm{Pt}_{32}+\mathrm{Au}_{32}$ (40 [blue], $70,100,110,115$ [red] $\left.{ }^{\circ} \mathrm{C}\right)$

heated to desorb CO (Figure 6), this stretching frequency shifts from $2085 \mathrm{~cm}^{-1}$ to $2075 \mathrm{~cm}^{-1}$ because of decreased coupling between adsorbed $\mathrm{CO}$ molecules. ${ }^{45}$ The band intensity is relatively constant until the temperature reaches $140{ }^{\circ} \mathrm{C}$ and $\mathrm{CO}$ rapidly desorbs from the surface. Infrared spectra of $\mathrm{Pt}_{32}+\mathrm{Au}_{32}$ largely resemble $\mathrm{Pt}_{32}$ spectra, with the exception of a small shoulder at approximately $2050 \mathrm{~cm}^{-1}$. This shoulder may suggest the presence of some bimetallic sites (vida infra) and that a small fraction of the $\mathrm{Pt}$ has been incorporated into Au particles. ${ }^{11,22,23}$

Closer inspection of the $\mathrm{Pt}_{16} \mathrm{Au}_{16}$ desorption experiment suggests that the broad room-temperature $\mathrm{Pt}-\mathrm{CO}$ band may be better described as two bands at 2065 and $2050 \mathrm{~cm}^{-1}$. Upon heating the sample, changes in the $\mathrm{Pt}-\mathrm{CO}$ band are due to a substantial increase in the intensity of the $2050 \mathrm{~cm}^{-1}$ band. Once $\mathrm{CO}$ completely desorbs from $\mathrm{Au}$, the $\mathrm{Pt}-\mathrm{CO}$ band becomes substantially more symmetric and the $2065 \mathrm{~cm}^{-1}$ band is no longer distinguishable. Complete desorption of the $2050 \mathrm{~cm}^{-1}$ band also occurs at a substantially higher temperature than with 
the $\mathrm{Pt}_{32}$ or $\mathrm{Pt}_{32}+\mathrm{Au}_{32}$ samples, suggesting that $\mathrm{CO}$ is more strongly bound to the well mixed bimetallic NPs.

We believe that this phenomenon is best explained by a $\mathrm{CO}$ induced restructuring of the $\mathrm{Pt}-\mathrm{Au}$ NPs. Au has a lower work function than $\mathrm{Pt}$ and, in the absence of ligands, Au is more stable at the surface of $\mathrm{Pt}-\mathrm{Au}$ alloys or bimetallic NPs. ${ }^{46,47}$ However, $\mathrm{CO}$ forms strong bonds with $\mathrm{Pt}^{0}$ and provides a driving force for pulling Pt to the particle surface. ${ }^{46}$ The fluxional behavior of Pt NPs has also been suggested by Somorjai and coworkers. ${ }^{48}$ For $\mathrm{Pt}_{16} \mathrm{Au}_{16}$, this restructuring appears to be an activated process near room temperature, as increasing temperature provides the energy required to rearrange the NP and draw Pt to the surface.

Similar behavior has been suggested for dilute alloys of $\mathrm{Pt}$ in Au. ${ }^{13,46}$ In particular, Dumesic and co-workers have examined $\mathrm{CO}$ adsorbed on a supported $\mathrm{Pt}-\mathrm{Au} / \mathrm{SiO}_{2}$ catalyst prepared with metal ratios in the miscibility range. ${ }^{13}$ Their method prepared bimetallic $\mathrm{Pt}-\mathrm{Au}$ NPs of $2-5 \mathrm{~nm}$ in diameter, which coexisted with numerous large (ca. $200 \mathrm{~nm}$ ) Au particles. Infrared spectra of $\mathrm{CO}$ adsorbed on their catalyst indicated a predominantly $\mathrm{Au}$ surface at $203 \mathrm{~K}$. Although no restructuring was observed, adsorption at ambient temperatures indicated that the surface was substantially enriched in Pt relative to the low-temperature spectrum. The room-temperature spectra reported by Dumesic's group $^{13}$ are also consistent with spectra for $\mathrm{CO}$ adsorbed on $\mathrm{Pt}-\mathrm{Au}$ NPs prepared from organometallic clusters. ${ }^{11,22,49,50}$

The mobility of Pt and Au within the bimetallic NPs may also help to explain why the particles on $\mathrm{Pt}_{16} \mathrm{Au}_{16}$ remain small after fairly forcing activation conditions $\left(8 \mathrm{~h}\right.$ at $\left.300{ }^{\circ} \mathrm{C}\right)$. The incorporation of Pt into the NP clearly anchors $\mathrm{Au}$ to the support, preventing the severe particle agglomeration that is so prevalent in monometallic $\mathrm{Au} / \mathrm{SiO}_{2}$ catalysts. ${ }^{13,20,24,49}$ The apparent mobility of $\mathrm{Pt}$ atoms within the $\mathrm{Pt}_{16} \mathrm{Au}_{16} \mathrm{NPs}$ may allow Pt to initially concentrate at the silica-NP interface at low temperatures. The low-temperature restructuring would be particularly important for anchoring $\mathrm{Au}$ onto silica because $\mathrm{Au}$ NPs are mobile on silica surfaces at temperatures as low as $100{ }^{\circ} \mathrm{C} .{ }^{20,51}$ Continuing work in our lab is aimed at understanding the effects of particle size and composition on this phenomenon, as well as temperature and ligand effects.

CO Oxidation Catalysis. Figure 7 shows $\mathrm{CO}$ oxidation catalysis data from freshly activated catalysts. The activity of the monometallic $\mathrm{Pt}_{32}$ catalyst is similar to other dendrimer derived Pt catalysts and to traditional catalysts prepared by wetness impregnation. ${ }^{34}$ Under these conditions, Pt shows little activity below $90{ }^{\circ} \mathrm{C}$; above this temperature, activity increases rapidly. The $\mathrm{Au}_{32}$ catalyst is essentially inactive, consistent with most reports of $\mathrm{SiO}_{2}$ being inappropriate for preparing active supported $\mathrm{Au}$ catalysts. ${ }^{7,20}$ The cometallic $\mathrm{Pt}_{32}+\mathrm{Au}_{32}$ catalyst has essentially the same features as $\mathrm{Pt}_{32}$, except the activity is delayed by about $25^{\circ} \mathrm{C}$, suggesting there may be less surface $\mathrm{Pt}$ available for catalysis.

$\mathrm{CO}$ oxidation catalysis by $\mathrm{Pt}_{16} \mathrm{Au}_{16}$ shows three distinct regions of activity; most notably, there is substantial activity at

(46) Bouwman, R.; Sachtler, W. H. M. J. Catal. 1970, 19, 127.

(47) Okamoto, H.; Massalski, T. B. Bull. Alloy Phase Diagrans 1985, 6, 4656.

(48) Somorjai, G. A.; Hwang, K. S.; Parker, J. S. Top. Catal. 2003, 26, 87-99.

(49) Mihut, C.; Chandler, B. D.; Amiridis, M. D. Catal. Commun. 2002, 3, 9197.

(50) Chandler, B. D.; Pignolet, L. H. Catal. Today 2001, 65, 39-50.

(51) Yang, C.-M.; Kalwei, M.; Schuth, F.; Chao, K.-J. Appl. Catal., A 2003, $254,289-296$.

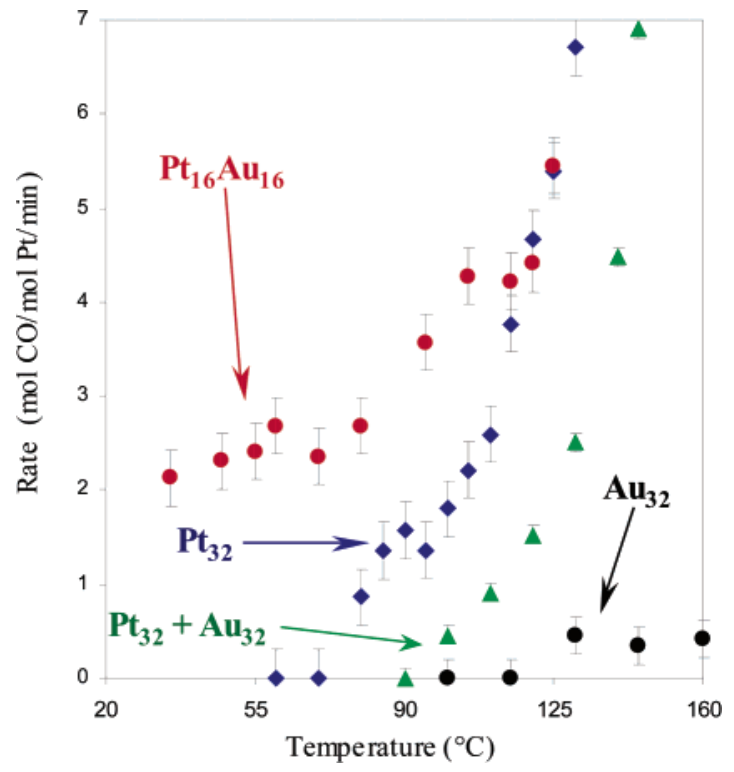

Figure 7. $\mathrm{CO}$ oxidation catalysis by silica supported $\mathrm{Pt}_{32}, \mathrm{Au}_{32}, \mathrm{Pt}_{16} \mathrm{Au}_{16} \mathrm{Pt}$, and $\mathrm{Pt}_{32}+\mathrm{Au}_{32}$ NPs. Rate is reported as moles $\mathrm{CO}$ converted per total moles $\mathrm{Pt}$ per minute; for $\mathrm{Au}_{32}$, the rate is in moles $\mathrm{CO}$ converted per total mole Au per minute.

low temperatures $\left(30-80{ }^{\circ} \mathrm{C}\right)$. We suggest that this activity is due either to $\mathrm{Au}$ or possibly to $\mathrm{Pt}-\mathrm{Au}$ bimetallic sites on the catalyst. At temperatures of $120{ }^{\circ} \mathrm{C}$ or higher, the catalyst is indistinguishable from $\mathrm{Pt}_{32}$ and is consistent with monometallic Pt catalysts. ${ }^{34}$ Presumably, surface Pt atoms are very active at these temperatures and are responsible for essentially all of the catalysis. In the intermediate temperature range $\left(80-120{ }^{\circ} \mathrm{C}\right.$, where Pt begins to become active), both metals or types of sites may be active. Alternately, Au may be promoting $\mathrm{CO}$ oxidation catalysis by $\mathrm{Pt}$ at these temperatures, possibly by breaking up Pt ensembles or providing weak $\mathrm{CO}$ or $\mathrm{O}_{2}$ adsorption sites. ${ }^{52,53}$

Supported Au NPs are well known to be highly active lowtemperature $\mathrm{CO}$ oxidation catalysts; ${ }^{7,20,54}$ however, the most active catalysts utilize reducible oxide supports such as $\mathrm{TiO}_{2}{ }^{7,20}$ Although the identity of the active catalyst is still under substantial debate, ${ }^{55}$ catalytic activity is most commonly associated with the preparation and stabilization of small-metal NPs on the support. ${ }^{56}$ The preparation of active Au catalysts is also extremely sensitive to the preparation method employed. Most of the active gold catalysts have been prepared using the "deposition-precipitation" method; however, some other methods (CVD, activation of organometallic complexes) are also suitable for preparing and stabilizing highly dispersed Au NPs on a variety of supports. ${ }^{7,20}$ Silica, being mildly acidic and having a low isoelectric point, is unsuitable for the depositionprecipitation method because the surface is negatively charged at $\mathrm{pHs}$ required to precipitate $\mathrm{Au}(\mathrm{OH})_{x}$ on a support. Additionally, silica does not effectively stabilize gold NPs against agglomeration. ${ }^{20}$

Only a few $\mathrm{Au} / \mathrm{SiO}_{2}$ catalysts have been reported to be active near room temperature. ${ }^{51,57}$ Schüth et al. deposited auric acid

(52) Bourane, A.; Bianchi, D. J. Catal. 2004, 222, 499-510.

(53) Fanson, P. T.; Delgass, W. N.; Lauterbach, J. J. Catal. 2001, 204, 35-52.

(54) Lin, S. D.; Bollinger, M.; Vannice, M. A. Catal. Lett. 1993, 17, 245.

(55) Guzman, J.; Gates, B. C. J. Am. Chem. Soc. 2004, 126, 2672-2673.

(56) Valden, M.; Lai, X.; Goodman, D. W. Science 1998, 281, 5383.

(57) Okumura, M.; Nakamura, S.; Tsubota, S.; Nakamura, T.; Azuma, M.; Haruta, M. Catal. Lett. 1998, 51, 53-58.

12954 J. AM. CHEM. SOC. - VOL. 126, NO. 40, 2004 
onto SBA-15 mesoporous silica that had been functionalized with positively charged groups. Reduction with $\mathrm{NaBH}_{4}$ yielded supported particles approximately $4.5 \mathrm{~nm}$ in diameter; the resulting material had an activity of $2.7 \times 10^{-4} \mathrm{mmol} / \mathrm{g}_{\text {cat }} / \mathrm{sec}$ $(0.073 \mathrm{~mol} / \mathrm{mol} \mathrm{Au} / \mathrm{min})$ at $30{ }^{\circ} \mathrm{C}$. This catalyst was not thermally stable and began to deactivate at $100{ }^{\circ} \mathrm{C}$. It became completely inactive after $20 \mathrm{~min}$ at $160{ }^{\circ} \mathrm{C}$. Haruta et al. have also reported on an $\mathrm{Au} / \mathrm{SiO}_{2}$ catalyst prepared via chemical vapor deposition of the organometallic Au complex $\left(\mathrm{CH}_{3}\right)_{2} \mathrm{Au}-$ $\left(\mathrm{CH}_{3} \mathrm{COCH}_{2} \mathrm{COCH}_{3}\right)$. After calcination at $400{ }^{\circ} \mathrm{C}$ for $4 \mathrm{~h}$, the average gold NP diameter was $6.6 \pm 3.8 \mathrm{~nm}$ and the catalyst's activity was approximately $2 \times 10^{-6} \mathrm{~mol} / \mathrm{g}_{\text {cat }} / \mathrm{sec}(0.4 \mathrm{~mol} \mathrm{CO} /$ $\mathrm{mol} \mathrm{Au} / \mathrm{min}$ ) at $30{ }^{\circ} \mathrm{C}$. Closer examination of the PSD for this catalyst indicates a bimodal distribution, with about $15 \%$ of the imaged particles smaller than $3 \mathrm{~nm}$.

The $\mathrm{Pt}_{16} \mathrm{Au}_{16}$ catalyst is substantially more resistant to particle agglomeration than these materials, having small particles even after treatment at $300{ }^{\circ} \mathrm{C}$ for $6+$ hours. The activity $\mathrm{Pt}_{16} \mathrm{Au}_{16}$ $\left(2 \mathrm{~mol} \mathrm{CO} / \mathrm{mol} \mathrm{Au} / \mathrm{min}\right.$ at $30{ }^{\circ} \mathrm{C}$, assigning all activity at this temperature to $\mathrm{Au}$ ) is quite consistent with Haruta's $\mathrm{Au} / \mathrm{SiO}_{2}$ catalyst, with the greater activity of our material coinciding with a greater fraction of particles $3 \mathrm{~nm}$ or smaller. It is difficult to unequivocally determine the role of $\mathrm{Pt}$ in the low-temperature activity, and it is possible that bimetallic sites are responsible for the catalysis. We favor a simpler explanation in which the primary role of $\mathrm{Pt}$ is to help stabilize smaller particles. It is possible that $\mathrm{Pt}$ adds additional functionality to the catalyst by not only binding $\mathrm{O}_{2}$ but also locating bound or activated $\mathrm{O}_{2}$ near active $\mathrm{Au}$ sites. However, the strong binding of $\mathrm{CO}$ to $\mathrm{Pt}$ on $\mathrm{Pt}_{16} \mathrm{Au}_{16}$ and the similar activity to Haruta's Au only material tend to support the premise that the activity is primarily associated with $\mathrm{Au}$. We believe that the $\mathrm{Pt}_{16} \mathrm{Au}_{16}$ catalytic behavior is best described by bimetallic NPs in which Au sites are active at low temperatures and Pt sites take over at higher temperatures, when $\mathrm{CO}$ is less strongly bound to the surface.

\section{Summary and Conclusions}

Using preformed $\mathrm{Cu}^{0} \mathrm{NPs}$ in hydroxyl terminated PAMAM dendrimers, supported bimetallic $\mathrm{Pt}-\mathrm{Au}$ NPs within the bulk miscibility gap were prepared. After dendrimer removal, the supported NPs remained small as most were smaller than $3 \mathrm{~nm}$. TEM, EDS, and infrared spectroscopy of adsorbed CO confirmed the bimetallic nature of the NPs. The size and composition of the particles are particularly noteworthy given the propensity of silica supported Au particles to agglomerate during thermal treatments. Infrared spectroscopy of adsorbed $\mathrm{CO}$ indicated the presence of $\mathrm{Pt}$ and $\mathrm{Au}$ sites capable of binding $\mathrm{CO}$. Evidence for a $\mathrm{CO}$ adsorbed on $\mathrm{Pt}$ in a bimetallic site was suggested by the presence of a strong band at $2050 \mathrm{~cm}^{-1}$, consistent with literature precedents. $\mathrm{CO}$ desorption experiments also showed anomalous behavior as the $\mathrm{Pt}-\mathrm{CO}$ band increased in intensity as the $\mathrm{Au}-\mathrm{CO}$ band intensity decreased. Relative to other silica based catalysts, the supported $\mathrm{Pt}-\mathrm{Au}$ NPs were highly active $\mathrm{CO}$ oxidation catalysts at ambient temperatures.

A model was proposed to help understand the behavior and thermal stability of the bimetallic NPs. The CO desorption data suggests that the NPs have fluxional structures and that strong ligands are capable of drawing Pt to the particle surface at moderate temperatures. We suggest that the strong bonds between surface oxides and platinum effectively concentrate $\mathrm{Pt}$ at the particle-support interface either during deposition or dendrimer removal. This internal migration effectively anchors the bimetallic NPs to the support, reducing their mobility and slowing particle agglomeration processes. The stabilization of small Au NPs appears to be critically important for their catalytic activity when supported on silica. Low-temperature catalytic activity is likely due to catalysis by gold, but bimetallic sites may also play an important role.

\section{Experimental Section}

Materials. All solutions were prepared using Nanopure water. Hydroxy-terminated generation 5 starburst polyamidoamine (PAMAM) dendrimers $(\mathrm{G} 5-\mathrm{OH})$ were obtained as a $5 \%$ solution in methanol (Aldrich). Prior to use, methanol was removed by rotary evaporation at room temperature. $\mathrm{K}_{2} \mathrm{PtCl}_{4}, \mathrm{NaBH}_{4}$ and $\mathrm{Cu}\left(\mathrm{NO}_{3}\right)_{2} \cdot x \mathrm{H}_{2} \mathrm{O}$ were purchased from Aldrich and used as received. $\mathrm{HAuCl}_{4}$ was obtained from Strem Chemicals. Silica (DAVICAT SI-1403, $245 \mathrm{~m}^{2} / \mathrm{g}$ ) was supplied by W. R. Grace. $\mathrm{O}_{2}, \mathrm{H}_{2}$, and $\mathrm{He}$ gases are all UHP grade from Airgas. Carbon monoxide ( $99.8 \%$ in aluminum cylinder) was purchased from Matheson Tri-Gas.

Preparation of Dendrimer-Stabilized Pt and Au Bimetallic Nanoparticles (DSNs). Dendrimer-stabilized Pt and Au bimetallic NP catalysts were prepared by adapting a literature method. ${ }^{33}$ All manipulations were performed under $\mathrm{N}_{2}$ using standard Schlenk techniques. Twenty milliliters of G5-OH $(0.01 \mathrm{mM})$ was mixed with $1.6 \mathrm{~mL} \mathrm{Cu}$ $\left(\mathrm{NO}_{3}\right)_{2}(5 \mathrm{mM})$ at $\mathrm{pH} 7.0-7.5$ and degassed for $20 \mathrm{~min}$. A 3-fold molar excess of $\mathrm{NaBH}_{4}$ was added to prepare $\left(\mathrm{G} 5-\mathrm{OH}(\mathrm{Cu})_{40}\right)$ nanocomposites. After $30 \mathrm{~min}$, the $\mathrm{pH}$ of the resulting brown solution was adjusted to 3.0 with $\mathrm{HClO}_{4}$ and stirred for $1 \mathrm{~h}$. Solutions of $\mathrm{K}_{2} \mathrm{PtCl}_{4}(0.64 \mathrm{~mL}, 5$ $\mathrm{mM})$ and $\mathrm{HAuCl}_{4}(1.6 \mathrm{~mL}, 2 \mathrm{mM})$ were degassed separately, mixed, and immediately added to the $\mathrm{G} 5-\mathrm{OH}(\mathrm{Cu})_{40}$ nanocomposite solution. The mixed solution was stirred for an additional $1-2 \mathrm{~h}$ and deposited onto the solid supports (see below).

The synthesis of dendrimer-stabilized Pt or Au monometallic NPs by $\mathrm{Cu}$ displacement was similar to the above method. For $\mathrm{Pt}_{32}, 0.2$ $\mu$ mol G5-OH $(\mathrm{Cu})_{32}$ nanocomposites were prepared, and $1.28 \mathrm{~mL}(5 \mathrm{mM})$ of $\mathrm{K}_{2} \mathrm{PtCl}_{4}$ solution was added to prepare $\mathrm{Pt}_{32} \mathrm{NPs}$. To make $\mathrm{Au}_{32} \mathrm{NPs}$, $3.2 \mathrm{~mL}(2 \mathrm{mM})$ of $\mathrm{HAuCl}_{4}$ solution was mixed with $0.2 \mu \mathrm{mol}$ $\mathrm{G} 5-\mathrm{OH}(\mathrm{Cu})_{48}$. In all cases, the NPs were immediately deposited onto the support.

Deposition and Activation. The resulting DSNs were deposited onto silica support via slow adsorption. The $\mathrm{pH}$ of DSN solution was adjusted to $8.5-9, \mathrm{SiO}_{2}$ was added, and the suspension was stirred overnight. The resulting dark solid was separated from the colorless mother liquor with a fine frit. The wet solid catalysts were stirred with saturated EDTA solution at $\mathrm{pH} 7.0-8.0$ for $15-20 \mathrm{~min}$ and then filtered and washed with deionized water. The EDTA wash was repeated three times. The catalyst was washed several times with deionized water and dried in a vacuum oven at $50{ }^{\circ} \mathrm{C}$ overnight. The yields of Pt and Au DSNs were generally about $70-75 \%$ and $\mathrm{Cu}$ residual was always less than $0.01 \%$. Supported DSNs were activated as described previously $\left(300{ }^{\circ} \mathrm{C}\right.$ for 4 h under $\mathrm{O}_{2}$ followed by $300{ }^{\circ} \mathrm{C}$ under $\mathrm{H}_{2}$ for $2 \mathrm{~h}$ ). ${ }^{34}$

$\mathrm{Pt}$ and Au analysis with Atomic Absorption Spectroscopy. $\mathrm{Pt}$ and Au loadings on catalysts were determined with a Varian SpectrAA 220FS atomic absorption spectrometer using an acetylene/air flame, as described previously. ${ }^{34}$ Briefly, the sample was treated with freshly prepared aqua regia and the $\mathrm{pH}$ was adjusted to 6.0-7.0 with ammonium hydroxide. The resulting solution was condensed and transferred to a 10 -mL volumetric flask containing sufficient $\mathrm{La}\left(\mathrm{NO}_{3}\right)_{3}$ to yield a final solution of $1 \% \mathrm{La}$. AA standards were prepared from Aldrich AA standard solutions and deionized water.

In-Situ FT-IR Experiments. FTIR spectra were collected using a Thermo Nicolet Nexus 470 spectrometer equipped with a DTGS detector with a resolution of $2 \mathrm{~cm}^{-1}$. A water-cooled stainless steel IR flow cell with $\mathrm{NaCl}$ windows was used to hold a pressed catalyst wafer 
(17-19 mg). The optical bench and beam path (outside the flow cell) were continuously purged with $\mathrm{N}_{2}$. A heating element wrapped around the cell with a thermocouple placed in close proximity to the catalyst sample allowed for in-situ heating of samples and collection spectra at different temperatures. All spectra were collected with gases flowing at $30 \mathrm{~mL} / \mathrm{min}$. Gas composition was manipulated by adjusting rotameters on an external manifold.

$\mathrm{CO}$ adsorption experiments were carried out after in-situ reduction $\left(20 \% \mathrm{H}_{2} / \mathrm{He}\right.$ at $300{ }^{\circ} \mathrm{C}$ for $2 \mathrm{~h}$ ) and flushing with $\mathrm{He}$ for $1 \mathrm{~h}$ at $300{ }^{\circ} \mathrm{C}$. Samples were then cooled under He flow to room temperature and a background spectrum was collected. A 5\% $\mathrm{CO} / \mathrm{He}$ mixture was flowed over the sample for $15 \mathrm{~min}$, followed by pure He. IR spectra of CO adsorbed on the catalyst surface were collected after all the gas-phase $\mathrm{CO}$ had been purged from the sample. $\mathrm{CO}$ desorption was accomplished by heating the sample under flowing $\mathrm{He}$.

CO Oxidation Catalysis. CO oxidation experiments were performed as described previously. ${ }^{34}$ Briefly, diluted $20 \mathrm{mg}$ of catalyst was diluted with $\alpha-\mathrm{Al}_{2} \mathrm{O}_{3}$ and placed in a single pass plug flow microreactor. Catalytic activity used a feed composition of $1.1 \% \mathrm{CO}$ and $20 \% \mathrm{O}_{2}$. Feed and reactor effluent composition was measured via gas chromatography using a TCD detector. Consequently, the feed flow rate was held constant at $26 \mathrm{~mL} / \mathrm{min}$ (space velocity $75000 \mathrm{hr}^{-1}$ ) and conversion was measured as a function of temperature. Rate data was determined only when conversion was less than $10 \%$.

TEM and EDS Analysis. $\mathrm{SiO}_{2}$-supported catalysts were suspended in dichloroethane and sonicated for $5 \mathrm{~min}$. TEM samples were prepared by placing a drop of the suspension on a copper grid (200 mesh, PELCO) with a thin carbon coating. Transmission electron microscopy (TEM) was performed on a JEOL $2010 \mathrm{~F}$ operating at $200 \mathrm{kV}$ equipped with an INCAEnergyTEM EDS System with a $30 \mathrm{~mm}^{2} \mathrm{Li}$ drifted detector calibrated using the zero loss and $\mathrm{Cu} \mathrm{K}$ and $\mathrm{L}$ lines. EDS spectra for individual particles were collected with a $0.5-\mathrm{nm}$ beam diameter for an acquisition time of $2 \mathrm{~min}$. EDS data was treated using the Cliff-Lorimer quantitation method. ${ }^{58}$

Acknowledgment. We gratefully acknowledge the Robert A. Welch Foundation (Grant Number W-1552) for financial support of this work. Acknowledgement is made to the donors for the American Chemical Society Petroleum Research Fund for partial support of this research. We also thank Prof. D. Wayne Goodman and Prof. Richard M. Crooks from Texas A\&M University for their input and helpful discussions.

Supporting Information Available: Representative TEM micrographs and TEM particle size distributions for all catalysts. Representative EDS spectrum for $\mathrm{Pt}_{16} \mathrm{Au}_{16}$; IR spectrum of $\mathrm{Au}_{32}$ after treatment with $\mathrm{CO}$ and flushing with He. This material is available free of charge via the Internet at http://pubs.acs.org. JA046542O

(58) Cliff, G.; Lorimer, G. W. J. Microsc. 1975, 103, 179. 